\title{
Nutritional Status of Patients on Maintenance Hemodialysis in a Tertiary Referral Hospital of Nepal
}

\author{
Abhishek Maskey, Yukta Narayan Regmi and Sushant Katwal
}

Department of Medicine, Manipal Teaching Hospital, Pokhara, Nepal.

\begin{abstract}
Introduction: Malnutrition is a common problem in hemodialysis patient, which is associated with increased mortality and morbidity. There is paucity of data regarding the nutritional status of patient on maintenance hemodialysis in developing countries. This study attempts to access nutritional status of patients on hemodialysis in tertiary referral hospital on western region of Nepal and correlate it with biochemical and laboratory parameters.

Methods: A total of fifty patients on hemodialysis were evaluated. Nutritional assessment was made by Subjective Global Assessment (SGA) score, anthropometrics [Body Mass Index (BMI), Triceps Skin Fold Thickness (TSF), Mid Arm Circumference (MAC), Mid Arm Muscle Circumference (MAMC) and biochemical tests.

Results: The study assessed 50 patients (34 males and 16 females) with mean age of $54 \pm 14$ years. Seventy eight percent (39) patients had mild to moderate malnutrition. Anthropometric parameters like BMI, TSF, MAC with normal nutrition were significantly higher than in patients with mild to moderate malnutrition. Malnutrition score (MS) by SGA significantly correlated with duration of dialysis. However, serum albumin was not statistically significant. Conclusion: Malnutrition is very common in patients undergoing hemodialysis with SGA having significant correlation with duration of dialysis. Routine nutritional monitoring among such patients are extremely important for diagnosing malnutrition early on, thus preventing complications and reducing the morbidity and mortality rates in this population.
\end{abstract}

Keywords: anthropometric measurement; hemodialysis; malnutrition score; nutritional status

\section{INTRODUCTION}

Protein energy malnutrition (PEM) is common in maintenance hemodialysis (MHD) patients. The pathophysiology of PEM in this population is complex and involves great number of factors viz changes to energy metabolism and calorie level, hormonal disorder, poor food intake, anorexia, nausea, vomiting, nutritional loss during hemodialysis (HD), lactic acidosis relating to constant state of inflammation and uremic toxicity and occurrence of concomitant infection and inflammation. $^{1-3}$

Several studies have documented malnutrition in upto $23-70 \%$ of patients on HD and $18-50 \%$ of patients on peritoneal dialysis. ${ }^{4-5}$ Nutritional markers such as serum albumin and low body mass index are associated with higher mortality

Correspondence: Abhishek Maskey. Department of Medicine, Manipal Teaching Hospital, Pokhara, Nepal. Email: maskev21@hotmail.com 
rates in this population. ${ }^{6}$ Nutritional status and dialysis adequacy are considered major determinants of mortality and morbidity in patients undergoing MHD. ${ }^{7}$

Nutritional status is frequently ignored in many dialysis centers even though simple methods of nutritional assessment could have favorable impact on patient management. ${ }^{8-9}$ Periodical monitoring of the nutritional status in dialysis patients is crucial for preventing, diagnosing and treating PEM. Subjective Global Assessment (SGA) is a useful and reproducible instrument for assessing the nutritional status of dialysis patients. Because of its strength, National Kidney Foundation Kidney Disease/ Dialysis Outcome and Quality Initiative (NKF/ KDOQI) recommends assessing nutritional status of patients undergoing MHD by using SGA at least once in every six months. ${ }^{10}$ SGA is low in cost, simple, easy to perform and different studies have shown it to be a predictor of mortality. ${ }^{11}$
In Nepal, there is a high prevalence of PEM in MHD patients. ${ }^{12-13}$ There is a paucity of data on the assessment of nutritional status in MHD patients in Western region of Nepal. The aim of this study is to assess the nutritional status of the patient on MHD by using SGA for assessing nutritional status of our patients on MHD and compare it with biochemical and anthropometric measurements.

\section{METHODS}

Cross-sectional descriptive analytic study was conducted in the hemodialysis Unit, Manipal Teaching Hospital, Pokhara from $1^{\text {st }}$ July 2015 to $31^{\text {st }}$ December 2015.

A total of 50 patients on MHD for at least six months were included in the study. Patients with active infections, history of hospital admission for the past one month, severe hepatic or gastrointestinal diseases and patients from advanced senility or dementia that might interfere with understanding the questionnaire were excluded from the study.

Table 1: Table 1: Demographic data of study population according to gender.

\begin{tabular}{|l|c|c|c|}
\hline Parameters & $\begin{array}{c}\text { Total } \\
\text { Mean } \pm \text { SD }\end{array}$ & $\begin{array}{c}\text { Male } \\
\text { Mean } \pm \text { SD }\end{array}$ & $\begin{array}{c}\text { Female } \\
\text { Mean } \pm \text { SD }\end{array}$ \\
\hline Age (years) & $54 \pm 14$ & $53.91 \pm 15.98$ & $54 \pm 10.45$ \\
\hline Height (cm) & $155.8 \pm 8.23$ & $159 \pm 6.24$ & $147 \pm 4.24$ \\
\hline Weight (Kg) & $51.84 \pm 7.01$ & $53.67 \pm 6.09$ & $47.9 \pm 7.41$ \\
\hline Body mass index & $18.26 \pm 2.78$ & $18.80 \pm 2.30$ & $18.72 \pm 3.57$ \\
\hline Tricep skin fold & $6.46 \pm 2.27$ & $6.31 \pm 2.09$ & $6.78 \pm 2.64$ \\
\hline Mid arm circumference & $20.55 \pm 2.6$ & $20.30 \pm 2.55$ & $20.5 \pm 2.82$ \\
\hline Mid arm muscle circumference & $18.57 \pm 2.6$ & $18.38 \pm 2.28$ & $18.97 \pm 3.25$ \\
\hline Dialysis malnutrition score & $13 \pm 2.7$ & $12.82 \pm 2.8$ & $11.87 \pm 2.52$ \\
\hline Duration (months) & $25.16 \pm 14.29$ & $23.79 \pm 12.73$ & $28.06 \pm 17.24$ \\
\hline Urea reduction ratio & $57.43 \pm 10.55$ & $56.46 \pm 11.64$ & $59.47 \pm 7.69$ \\
\hline K t/v & $1.03 \pm 0.34$ & $1.01 \pm 0.38$ & $1.05 \pm 0.23$ \\
\hline
\end{tabular}


Table 2: Laboratory findings of study population

\begin{tabular}{|c|c|}
\hline Lab parameters & Mean \pm SD \\
\hline Hemoglobin $(\mathrm{gm} / \mathrm{dl})$ & $9.03 \pm 1.37$ \\
\hline $\begin{array}{l}\text { Total leucocyte count (cells/ } \\
\text { mm3) }\end{array}$ & $6808 \pm 1589$ \\
\hline $\begin{array}{l}\text { Lymphocyte count (cells/ } \\
\text { mm3) }\end{array}$ & $1280 \pm 351.46$ \\
\hline Platelets (cells/mm3) & $186820 \pm 56$ \\
\hline Blood urea (mg/dl) & $171 \pm 44$ \\
\hline Serum creatinine $(\mathrm{mg} / \mathrm{dl})$ & $10.3 \pm 3.41$ \\
\hline Sodium (mmol/L) & $139 \pm 4.5$ \\
\hline Potassium (mmol/L) & $5.0 \pm 0.9$ \\
\hline Uric acid (mg/dl) & $6.16 \pm 2.04$ \\
\hline Serum albumin $(\mathrm{gm} / \mathrm{dl})$ & $3.8 \pm 0.4$ \\
\hline Serum calcium (mg/dl) & $7.91 \pm 1.43$ \\
\hline Phosphorus (mg/dl) & $6.05 \pm 1.76$ \\
\hline Total cholesterol (mg/dl) & $149 \pm 34.17$ \\
\hline $\begin{array}{l}\text { Low density lipoprotein }(\mathrm{mg} / \\
\mathrm{dl})\end{array}$ & $76 \pm 30$ \\
\hline Triglyceride (mg/dl) & $121 \pm 56$ \\
\hline $\begin{array}{l}\text { High density lipoprotein (mg/ } \\
\text { dl) }\end{array}$ & $42 \pm 11$ \\
\hline
\end{tabular}

On the day of evaluation, pre-dialysis blood samples were collected to estimate complete blood count, blood urea, serum creatinine, calcium, phosphate, total protein and albumin, qualitative CRP, and lipid profile and post dialysis urea to calculate urea reduction ratio and $\mathrm{Kt} / \mathrm{v}$ (dialysis adequacy). Patients were interviewed during dialysis regarding their dietary habit, change in weight, gastrointestinal symptoms, and all other information relevant to the SGA tool.

Anthropometric measurements were carried out 10-20 minutes after completion of MJSBH Vol 15 Issue 2 July-Dec 2016 hemodialysis. Height and body weight was measured with light clothing. Body mass index (BMI) was calculated as the ratio of end dialysis body weight in kilogram and the square of the height in meters $\left(\mathrm{kg} / \mathrm{m}^{2}\right)$. Measurements of skin fold in triceps muscle (TSF) was done with Vernier caliper to estimate body fat. Measurement of mid-arm circumference (MAC) was done with an inelastic measuring tape of length $150 \mathrm{~cm}$ on the nonaccess arm to estimate muscle mass. MAC signifies the thickness of subcutaneous fat and muscle. Mid-arm muscle circumference (MAMC), which reflects the protein store in the body, was calculated using the following formula: $\mathrm{MAMC}=\mathrm{MAC}-(3.1415 \times \mathrm{TSF}) .{ }^{14}$

Nutritional status was assessed by SGA that relied on seven components - weight change, dietary intake, gastrointestinal symptoms, functional capacity, comorbidity, subcutaneous fat, and signs of muscle wasting. Each component was given a score from 1 (normal) to 5 (very severe). Thus, dialysis malnutrition score (DMS), sum of all components, range from 7 (normal) to 35 (severely malnourished). DMS score between 7-10 was considered as well nourished. DMS score between 11-22 was considered as having mild to moderate malnutrition. Likewise a score between 23 and 35 was considered as severely malnourished. ${ }^{15}$, ${ }^{16}$ All the data collected were analyzed with the help of SPSS version 22.

\section{RESULTS}

The study population consisted of 34 males and 16 females patients with age ranging from 23 years to 83 years. Demographic and anthropometric parameters are shown in table 1. The duration of hemodialysis ranged from 6 months to 52 months with mean duration of $25.16 \pm 14.29$ months. MS classified patients 
Table 3: Nutritional assessment of study population according to anthropometric measurement

\begin{tabular}{|l|c|c|}
\hline $\begin{array}{l}\text { Anthropometric } \\
\text { measurements }\end{array}$ & $\begin{array}{c}\text { Normal } \\
\text { nutrition } \\
\mathbf{( 7 - 1 0 )}\end{array}$ & $\begin{array}{c}\text { Mild to } \\
\text { moderate } \\
\text { nutrition }\end{array}$ \\
\begin{tabular}{|l|c|c|}
$\mathbf{( 1 1 - 2 2 )}$ \\
$\mathbf{N = 3 9}$
\end{tabular} \\
\hline Body mass index & $21.33 \pm$ & $\begin{array}{c}18.05 \pm \\
1.03\end{array}$ \\
\hline $\begin{array}{l}\text { Tricep skin fold } \\
\text { thickness }\end{array}$ & $9.2 \pm 1.39$ & $5.71 \pm 1.79$ \\
\hline $\begin{array}{l}\text { Mid arm } \\
\text { circumference }\end{array}$ & $22.5 \pm 2.32$ & $19.66 \pm$ \\
\hline $\begin{array}{l}\text { Midarm muscle } \\
\text { circumference }\end{array}$ & $20.18 \pm$ & $18.12 \pm$ \\
\hline
\end{tabular}

into normal nutrition in $22 \%$ (11) of the cases and mild to moderate malnutrition in $78 \%$ (39).

Laboratory findings of the study population is shown in table 2. Mean serum albumin, serum uric acid were normal whereas serum calcium level was low and phosphorus was high.
Anthropometric parameters like BMI, TSF, MAC with normal nutrition were significantly higher than patients with mild to moderate malnutrition (table 3).

Duration of maintenance hemodialysis between normal nutrition and malnourished patients was statistically significant. However, laboratory parameters were not statistically significant.

Correlations were done between malnutrition score and other parameters of the patients. There was significant correlation between malnutrition score and BMI, MAC and MAMC showing lower BMI, MAC, MAMC having higher nutritional score and hence stronger tendency towards malnutrition. There was also significant correlation between MS and MHD (table 5).

\section{DISCUSSION}

Malnutrition is common in hemodialysis patients and accounts for increased risk of

Table 4: Lab parameters by Malnutrition score

\begin{tabular}{|l|c|c|c|}
\hline Variables & Normal nutrition & Mild to moderate malnutrition & P Value \\
\hline Age & $50.63 \pm 16.02$ & $54.84 \pm 13.72$ & 0.38 \\
\hline Height (cm) & $156.27 \pm 8.18$ & $155.66 \pm 8.35$ & 0.83 \\
\hline Weight (kg) & $52.95 \pm 8.13$ & $51.52 \pm 6.74$ & 0.55 \\
\hline Hemoglobin (gm/d) & $8.9 \pm 1.30$ & $9.06 \pm 1.39$ & 0.729 \\
\hline Albumin (gm/dl) & $4.02 \pm 0.40$ & $3.75 \pm 0.42$ & 0.065 \\
\hline Total cholesterol (mg/dl) & $140.09 \pm 22.69$ & $151.77 \pm 36.60$ & 0.322 \\
\hline HDL- cholesterol (mg/dl) & $38.18 \pm 10.62$ & $43.62 \pm 11.12$ & 0.155 \\
\hline LDL- cholesterol (mg/dl) & $77.82 \pm 19.49$ & $75.97 \pm 32$ & 0.858 \\
\hline Triglyceride (mg/d) & $117.82 \pm 42.82$ & $122.46 \pm 59.22$ & 0.810 \\
\hline MHD (months) & $16.09 \pm 8.42$ & $27.72 \pm 14.63$ & 0.016 \\
\hline CRP Positive & $3 \%$ & $9 \%$ & 0.774 \\
\hline
\end{tabular}


morbidity and mortality. Unfortunately, evaluation of nutritional status of patients are usually not performed. Nutritional assessment of patients on $\mathrm{HD}$ is based on multiple indicators of nutritional status, including the assessment of visceral proteins deposits by the use of biochemical parameters and somatic deposits by the use of body composition weight, anthropometry, bioimpedence. ${ }^{4}$ This study attempts to assess the nutritional status of
HD patients and correlates the methods for evaluation of nutritional status.

Different literature from Nepal showed that malnutrition was present in $66 \%$ to $84 \%$ of patients undergoing HD. ${ }^{12-13}$ In our study, malnutrition was present in $78 \%$ of patients. The prevalence of malnutrition in different parts of the world in various literatures varied from $25 \%$ to $80 \%{ }^{4-5}$ This could be attributed to different criteria used for diagnosing nutritional

Table 5: Correlation of anthropometric measurements and lab parameters with malnutrition score

\begin{tabular}{|c|c|c|}
\hline Variables & Malnutrition score (r) & Pvalue \\
\hline Body mass index & -0.689 & $<0.001^{*}$ \\
\hline Tricep skin fold thickness & -0.484 & $<0.001 *$ \\
\hline Mid arm circumference & -0.642 & $<0.001^{*}$ \\
\hline Midarm muscle circumference & -0.554 & $<0.001^{*}$ \\
\hline Hemoglobin & -0.089 & 0.54 \\
\hline Blood urea & 0.27 & 0.55 \\
\hline Serum creatinine & -0.039 & 0.788 \\
\hline Sodium & -0.078 & 0.590 \\
\hline Potassium & -0.014 & 0.92 \\
\hline Uric acid & -215 & 0.133 \\
\hline Serum albumin & -0.237 & 0.090 \\
\hline Serum calcium & -0.188 & 0.191 \\
\hline Phosphorus & 0.161 & 0.264 \\
\hline Total cholesterol & 0.094 & 0.516 \\
\hline Low density lipoprotein & -0.044 & 0.76 \\
\hline Triglyceride & -0.118 & 0.415 \\
\hline High density lipoprotein & 0.171 & 0.234 \\
\hline Age & 0.121 & 0.401 \\
\hline Duration of HD & 0.410 & $0.003 *$ \\
\hline Urea reduction ratio & 0.056 & 0.699 \\
\hline $\mathbf{K t} / \mathbf{V}$ & 0.145 & 0.315 \\
\hline
\end{tabular}


status. Studies conducted in developing countries showed similar frequency of malnutrition as seen in our study. ${ }^{17}$ The reason for these similar findings may be due to poor dietary intake and low socioeconomic condition as these conditions are commonly encountered in the developing nations.

Among the biochemical parameters, albumin is a marker of protein storage. The International Society of Renal Nutrition and metabolism includes serum albumin $<3.8 \mathrm{gm} / \mathrm{dl}$ as one of the three biochemical diagnostic criteria for protein energy wasting. In our study, serum albumin level was not statistically significant and did not correlate with malnutrition score. Similar findings were observed in studies done in patients on hemodialysis. ${ }^{13},{ }^{18-19}$ It is probably due to relatively late manifestation of malnutrition, since albumin has a long half life, hepatic synthetic reserve is very large and fall in serum albumin level lag behind the onset of malnutrition. Hence, serum albumin is considered as indicator of malnutrition but not considered a reliable index.

Anthropometry is a common method of nutritional assessment. It may be reproducible and its sensitivity is $90 \% .{ }^{20}$ In this study, there is significant negative correlation between malnutrition and BMI, TSF, MAC, MAMC which shows that when anthropometric measurement decreases, there is increase MS. Studies conducted in Nepal and abroad show similar findings.12-13, 21-22 Therefore combination of these anthropometric parameters may be as effective as SGA for evaluation of malnutrition on hemodialysis population.

This study also shows that there is a strong correlation between duration of hemodialysis with MS. Similar findings were also reported MJSBH Vol 15 Issue 2 July-Dec 2016 in different parts of world. ${ }^{23-24}$ However, few studies have shown there is no significant correlation of duration of hemodialysis and malnutrition. ${ }^{13,25}$

\section{CONCLUSION}

Our study shows that $22 \%$ of the subjects were well nourished, $78 \%$ of the subjects were mild to moderately malnourished and none of the subjects were severely malnourished which was determined using MS. Our study does not show any positive correlation between MS and laboratory parameters but there was correlation between anthropometric measurements and duration of hemodialysis and MS. So SGA can be used to assess the degree of malnutrition in hemodialysis subjects.

\section{REFERENCES}

1. Todigo G, Aparicio M, Attman PO et al. Expert working group report on nutrition in adult patients with renal insufficiency. Clin Nutr. 2000; 19(3): 197-207. DOI: https:// doi.org/10.1054/clnu.1999.0130

2. Pupim LB, Cuppari L, Ikizler TA. Nutrition and metabolism in kidney disease. Semin Nephrol. 2006; 26(2):134-57. DOI: https:// doi.org/10.1016/j.semnephrol.2005.09.010

3. National Kidney Foundation. K/DOQI clinical practice guidelines for chronic kidney disease: evaluation, classification, and stratification. Am J Kidney Dis. 2002; 39(2 Suppl 1):S1-266.

4. Oliveira CM, Kubrusly M, Mota RS et al. Malnutrition in chronic kidney failure: what is the best diagnostic method to assess? J Bras Nefrol. 2010 Mar; 32(1):55-68.

5. Ikizler TA, Hakim RM. Nutrition in endstage renal disease. Kidney Int. 1996;50(2): 343-57. DOI: https://doi.org/10.1038/ki. 1996.323

6. Faintuch J, Morais AA, Silva MA et al. Nutritional profile and inflammatory status of hemodialysis patients. Ren Fail. 2006; 
28(4):295-301. DOI: https://doi.org/ $10.1080 / 08860220600577742$

7. Teixeira Nunes F, de Campos G, Xavier de Paula SM et al. Dialysis adequacy and nutritional status of hemodialysis patients. Hemodial Int'l 2008; 12: 45-51. DOI: h t t p s : / / d o i.org/ $10.1111 / \mathrm{j}$. 1542-4758.2008.00239.x

8. Kalantar-Zadeh K, Kopple JD. Relative contributions of nutrition and inflammation to clinical outcome in dialysis patients. Am J Kidney Dis. 2001; 38:1343-50. DOI: https://doi.org/10.1053/ajkd.2001.29250

9. Jones JM. The methodology of nutritional screening and assessment tools. J Hum Nutr Diet. 2002; 15:59-71. DOI: https://doi.org/ 10.1046/j.1365-277X.2002.00327.x

10. K/DOQI. Nutrition in chronic renal failure. Am J Kidney Dis. 2000; 35(6, suppl 2): S16-S25.

11.Van Manen JG, Korevaar JC et al. A comparison of different measures for nutritional status and their association with survival. J Am Soc Nephrol. 2002; 13:624-28.

12. Sedhain A, Rajani Hada R, Agrawal RK et al. Assessment of Nutritional Status of Nepalese Hemodialysis Patients by Anthropometric Examinations and Modified Quantitative Subjective Global Assessment. Nutrition and Metabolic Insights 2015:8 2127. DOI: https://doi.org/10.4137/ NMI.S27640

13. Manandhar DN, Chhetri PK, Pahari LR et al. Nutritional assessment of patients under hemodialysis in Nepal Medical College Teaching Hospital. Nepal Med Coll J 2008; 10(3): 164-69.

14. Weber J, Kelley J: Assessing nutrition. In: Health Assessment in Nursing, 3rd Ed., edited by Nieginski E, Philadelphia, Lippincott Williams \& Wilkins 2003, p 165

15. Kalantar-Zadeh K, Kleiner M, Dunne E et al. A modified quantitative subjective global assessment of nutrition for dialysis patients. Nephrol Dial Transplant. 1999; 14: 1732-8. DOI: https://doi.org/10.1093/ndt/ 14.7.1732
16. Afshar R, Sanavi S, Izadi-Khah A. Assessment of nutritional status in patients undergoing maintenance hemodialysis: a single-center study from Iran. Saudi J Kidney Dis Transpl 2007; 18: 397-404.

17. George A, Varsa $P$, Mathew $M$ et al. Malnutrition and nutrition therapy of chronic kidney disease in developing countries: Asian perspective. ACKD, 2003; 10: 213-21.

18. Mutsert R, Indeman F, Kretict RT et al. Association between serum albumin and mortality in dialysis patients is partly explained by inflammation and not by malnutrition. J Renal Nutrition. 2009; 19:127-35.DOI: https://doi.org/10.1053/ j.jrn.2008.08.003

19. Girija K, Radha R. Correlation between subjective global assessment (SGA) and serum albumin in hemodialysis patients. Int'l Journal of Recent Scientific Research 2015; 2:2790-93.

20. Nelson EE, Hong CD, Pesce AL et al. Anthropometric norms for the dialysis population. Am J Kidney Dis. 1990;16 (1): 32-7. DOI: https://doi.org/10.1016/ S0272-6386(12)80782-7

21. Janardhan V, Soundararajan P, Vanitha R. Prediction of Malnutrition Using Modified Subjective Global Assessment-dialysis Malnutrition Score in Patients on Hemodialysis. Indian Journal of Pharmaceutical Sciences 2011; 13: 38-45 DOI: https://doi.org/10.4103/0250-474X. 89755

22. Reema F, Majd T. Malnutrition and anthropometric and biochemical abnormalities in end-stage renal disease patients. Saudi Med J 2007; 28 (10): 1575-81

23. Koor BE, Nakhaie MR, Babaie S. Nutritional assessment and its correlation with anthropometric measurement in hemodialysis patients. Saudi J Kidney Dis Transpl 2015; 26: 697-701 DOI: https:// doi.org/10.4103/1319-2442.160146

24. Bashardoust B, Gavami M, Maleki N et al. Mortality and Nutritional Status in Patients 
Undergoing Hemodialysis. Shiraz E-Med J.

2015; 16(2): e20076. DOI: https://doi.org/

$10.17795 /$ semj 20076

25. Fatemeh E, Talayeh K, Esmaeili L. Evaluation of Malnutrition and its Association with Biochemical Parameters in Patients with End Stage Renal Disease Undergoing Hemodialysis Using Subjective Global Assessment. Nephro Urol Mon. 201; 6(3): e16385 